\title{
Genomics, transcriptomics, and peptidomics of neuropeptides and protein hormones in the red flour beetle Tribolium castaneum
}

\author{
Bin Li, ${ }^{1}$ Reinhard Predel, ${ }^{2}$ Susanne Neupert, ${ }^{2}$ Frank Hauser, ${ }^{3}$ Yoshiaki Tanaka, ${ }^{4}$ \\ Giuseppe Cazzamali, ${ }^{3}$ Michael Williamson, ${ }^{3}$ Yasuyuki Arakane, ${ }^{5}$ Peter Verleyen, ${ }^{6}$ \\ Liliane Schoofs, ${ }^{6}$ Joachim Schachtner, ${ }^{7}$ Cornelis J.P. Grimmelikhuijzen, ${ }^{3}$ \\ and Yoonseong Park ${ }^{1,8}$ \\ ${ }^{1}$ Department of Entomology, Kansas State University, Manhattan, Kansas 66506-4004, USA; ${ }^{2}$ Institute of Zoology, University \\ of Jena, D-07743 Jena, Germany; ${ }^{3}$ Center for Functional and Comparative Insect Genomics and Department of Cell Biology \\ and Comparative Zoology, Institute of Biology, University of Copenhagen, DK-2100 Copenhagen, Denmark; ${ }^{4}$ National Institute \\ of Agrobiological Science, Division of Insect Science, Tsukuba, Ibaraki 305-8634, Japan; ${ }^{5}$ Department of Biochemistry, Kansas \\ State University, Manhattan, Kansas 66506-4004, USA; ${ }^{6}$ Department of Animal Physiology and Neurobiology, University \\ of Leuven, BE-3000 Leuven, Belgium; ' Department of Animal Physiology, University of Marburg, D-35032 Marburg, Germany
}

\begin{abstract}
Neuropeptides and protein hormones are ancient molecules that mediate cell-to-cell communication. The whole genome sequence from the red flour beetle Tribolium castaneum, along with those from other insect species, provides an opportunity to study the evolution of the genes encoding neuropeptide and protein hormones. We identified 41 of these genes in the Tribolium genome by using a combination of bioinformatic and peptidomic approaches. These genes encode $>80$ mature neuropeptides and protein hormones, 49 peptides of which were experimentally identified by peptidomics of the central nervous system and other neuroendocrine organs. Twenty-three genes have orthologs in Drosophila melanogaster. Sixteen genes in five different groups are likely the result of recent gene expansions during beetle evolution. These five groups contain peptides related to antidiuretic factor-b (ADF-b), CRF-like diuretic hormone (DH37 and DH47 of Tribolium), adipokinetic hormone (AKH), eclosion hormone, and insulin-like peptide. In addition, we found a gene encoding an arginine-vasopressin-like (AVPL) peptide and one for its receptor. Both genes occur only in Tribolium and not in other holometabolous insects with a sequenced genome. The presence of many additional osmoregulatory peptides in Tribolium agrees well with its ability to live in very dry surroundings. In contrast to these extra genes, there are at least nine neuropeptide genes missing in Tribolium, including the genes encoding the prepropeptides for corazonin, kinin, and allatostatin-A. The cognate receptor genes for these three peptides also appear to be absent in the Tribolium genome. Our analysis of Tribolium indicates that, during insect evolution, genes for neuropeptides and protein hormones are often duplicated or lost.
\end{abstract}

[Supplemental material is available online at www.genome.org.]

Multicellular organisms use signaling molecules for cell-to-cell communication. Important among these signaling molecules are peptides and protein hormones which are produced in endocrine cells or neurons as larger precursors. These precursors (prepropeptides) are cleaved and further modified to yield mature peptides that are secreted into the extracellular environment. Peptides exert their action by binding to membrane receptors, mostly being G-protein coupled receptors (GPCRs), although some of them are receptor tyrosine kinases.

Studies of a number of insect species have provided invaluable information for understanding the function and the evolution of neuropeptides. Earlier studies on insect neuropeptides have used large physiological model species (i.e., locust, cockroach, and moth), and these have provided the groundwork for identifying the active signaling molecules. Further characterization of the functions of neuropeptides has been provided by re-

${ }^{8}$ Corresponding author.

E-mail ypark@ksu.edu; fax (785) 532-6232.

Article published online before print. Article and publication date are at http:// www.genome.org/cgi/doi/10.1101/gr.6714008. cent genetic studies in Drosophila melanogaster, examining the genetic null mutants and cell ablations of specific peptidergic cells (McNabb et al. 1997; Park et al. 2002a, 2003; Kim and Rulifson 2004; Isabel et al. 2005; Kim et al. 2006).

The earliest traceable representatives of ancestral neuropeptides and endocrine protein hormones date back to the most primitive metazoans, such as cnidarians (Grimmelikhuijzen et al. 2002). Furthermore, various neuropeptide signaling systems found in different metazoan taxa show considerable similarities, suggesting a common ancestor. For example, the neuropeptide arginine vasopressin (AVP) has in the course of evolution been conserved in both vertebrates (including mammals) and invertebrates including insects (as shown in this study), suggesting a common ancestor before the split of proto- and deuterostomia. Insulin and insulin-like growth factors are also highly conserved hormones in animals (Wu and Brown 2006).

Ortholog neuropeptide genes show a high degree of divergence in their overall amino acid sequences while only small portions of the genes have been highly conserved, namely, those regions coding for mature peptides or even only the motif within 
the peptide sequence that is required for biological activity (Liu et al. 2006a). Understanding of the evolution of the peptidergic signaling molecules has thus been hampered by the discontinuity of available data on evolutionarily related taxa, as well as by incomplete data within a particular species.

Another powerful approach to gain insight in the evolution of peptidergic signaling systems is based on the phylogeny of the cognate receptors for the neuropeptide ligands. G-protein coupled receptors are large transmembrane proteins that have been well conserved and that carry more informative sequences allowing the evolutionary analysis of the respective genes. This phylogenetic analysis, which of course assumes that ligands and cognate receptors co-evolve, allows evolutionary grouping of insect neuropeptides (Park et al. 2002b; Hauser et al. 2006a,b, 2007).

New techniques have recently emerged to identify the genes encoding neuropeptides. These new approaches include bioinformatic tools to predict the genes encoding neuropeptides from whole genome sequences and expressed sequence tag (EST) libraries, and direct detection of the processed mature peptides, using mass spectrometry (MS), also known as peptidomics (Hewes and Taghert 2001; Baggerman et al. 2002; Riehle et al. 2002; Predel et al. 2004; Hummon et al. 2006; Liu et al. 2006b). Upon identification of putative peptide encoding genes from the genome sequence, the transcription of these predicted genes can be confirmed by reverse-transcription PCR (RT-PCR) and by EST data. The amino acid sequence of the mature peptides obtained by peptidomic approaches can be compared with the predicted sequences, thereby revealing the mature peptide after posttranslational processing of the prepropeptide. As such, genomics, transcriptomics, and peptidomics approaches mutually support and supplement each other and lay the foundation for further functional investigations of the neuropeptides.

Genomic studies in the fruit fly, malaria mosquito, and honeybee have been highly successful and have identified 31, 32, and 36 neuropeptide genes, respectively (Hewes and Taghert 2001; Riehle et al. 2002; Hummon et al. 2006; Predel and Neupert 2007). These initial genomics surveys have been supported and elaborated by peptidomics data (Baggerman et al. 2002; Hummon et al. 2006; Predel and Neupert 2007). In the current paper, we have made a large collaborative effort to survey Tribolium neuropeptides at the genomic, transcriptomic, and peptidomic levels. In addition to providing large data sets on Tribolium neuropeptides, the present paper also gives important insights on the evolution of insect neuropeptides.

\section{Results and Discussion}

The current version of the genome sequence for Tribolium covers $>95 \%$ of the total genome with $>16,500$ genes in the computerized annotation (Tribolium Genome Sequencing Consortium, in prep.). Homology-based searches of neuropeptide and protein hormone genes identified 41 genes encoding $>80$ mature peptides carrying the typical signatures of neuropeptides. Tribolium EST database searches and RT-PCR on a subset of genes confirmed the existence of transcripts for 20 of these genes (Table 1; Supplemental Data 1). By using different mass spectrometric methods, the presence of 71 mature/processed peptides (with truncated and repetitive sequences), derived from 20 genes, was detected (Supplemental Data 2). Altogether, the expression of 30 neuropeptide genes was confirmed using these methods. Table 1 also shows the putative cognate Tribolium GPCRs for these peptides
(Hauser et al. 2007) as well as the homologous neuropeptides from other holometabolous insects.

\section{Mass spectrometric analyses}

In insects, the majority of the known bioactive neuropeptides contain a carboxy-terminal amide group (derived from a glycine residue preceding the cleavage sites in the precursor) which is important for their bioactivity and biostability (Eipper et al. 1993). In this context, it is noteworthy that our mass spectrometric analyses of brain and other nervous tissues revealed the expression of all predicted amidated neuropeptides from the genes encoding FMRFamides, tachykinin-related peptides (TKRPs), myosuppressin, allatostatin-B, short neuropeptide F, diuretic hormones (DH31 and DH47), adipokinetic hormone 2, SIFamide, ecdysis triggering hormone, and sulfakinins (Supplemental Data 1 and 2). In some cases, small peaks corresponding to truncated neuropeptides or other cleavage products from these prepropeptides were observed.

There are two genes in the upper group of Table 1, AKH-1 and $\mathrm{AKH}-3$, for which we could not detect the predicted amidated neuropeptides by MS. Furthermore, a putative pyrokinin with the C-terminal WFGPRLamide sequence (also named CAPApyrokinin, which is pyrokinin encoded by the capa-gene [Predel and Wegener 2006]; or pyrokinin-1, which is pyrokinin binding to the pyrokinin-1 receptor [Cazzamali et al. 2005]), was one of the peptides not detected in the mass spectrometric analyses (Fig. 1 ), whereas this peptide is present in nearly all other insects that were studied. The Tribolium pyrokinin gene encodes a second pyrokinin with the WFGPRLamide motif (Supplemental Data 1) that was also not detectable in our mass spectrometric analysis.

\section{Conserved and orthologous neuropeptide genes}

Most Tribolium neuropeptides and protein hormone sequences have clear counterparts in other insect species (Table 1), which can be identified by conserved sequence motifs, implying that parts of their genes may be under strong evolutionary pressure to be conserved.

Also the structure of the prepropeptide is often highly conserved in terms of the location of the immature peptides. For example, in the prepropeptide of adipokinetic hormone, proctolin, and SIFamide (Supplemental Data 1), the short neuropeptide sequences (5-12 amino acid residues long) are located immediately after the $\mathrm{N}$-terminal signal peptide and are tailed by longer associated peptides ( 40-120 amino acid residues long). In the case of ecdysis triggering hormone (ETH), the two peptides are consecutively located after the signal peptide (Supplemental Data 1). This ETH gene structure is conserved in other insects as well (Park et al. 1999; Zitnan et al. 2003).

Multiple repeated similar peptide sequences separated by cleavage sites are typical of other prepropeptides, including FMRFamide, allatostatin-B, CAPA, pyrokinin, and TKRPs with six, six, four, five, and eight repeats, respectively, in Tribolium (Supplemental Data 1). The numbers of repeats among the orthologs in different insect species may vary. For example, the allatostatin-B (also referred to as myoinhibitory peptide MIP), has six repeats in Tribolium but five, four, and thirteen repeats in $D$. melanogaster, Anopheles gambiae, and Bombyx mori, respectively.

The conservation of neuropeptide gene structure is extended to the conservation of alternative splicing patterns. For the ion transport peptide and the DH genes, for example, mutu-

\section{Genome Research}

www.genome.org 
Table 1. Neuropeptide and protein hormones identified by searching genome sequences of four holometabolous insects

T. castaneum

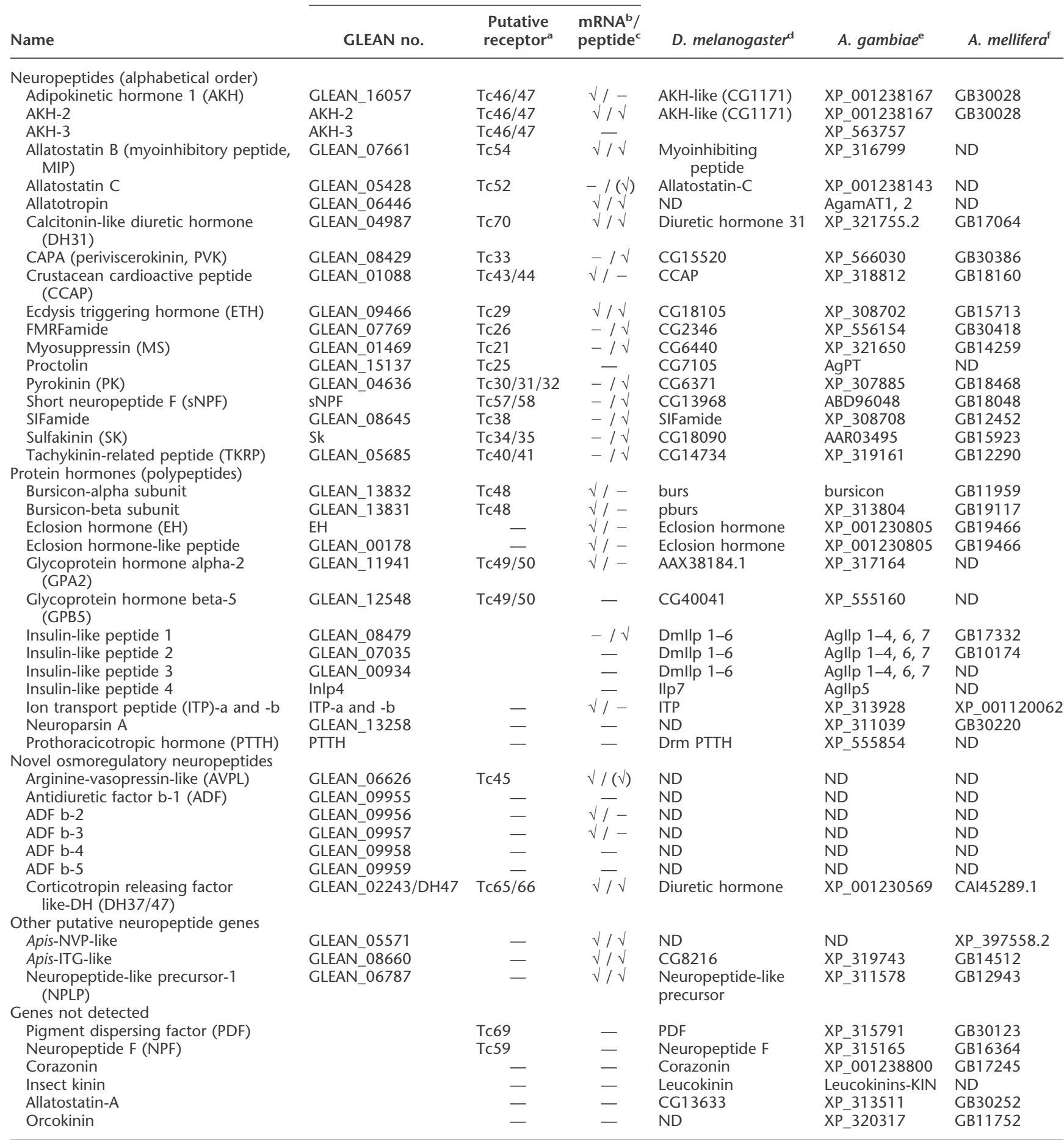

aData from Hauser et al. 2007.

bEvidence for transcriptions is either from EST or RT-PCR for partial or full-length mRNA.

'Detection of any peptide fragment for the annotated sequence is counted as positive for the gene. Parentheses in the evidence for peptides are the ones confirmed only by matching mass.

${ }^{\mathrm{d}}$ Drosophila melanogaster gene names are given for the peptide name, CG number, or GenBank accession numbers when available.

${ }^{\mathrm{e}}$ Anopheles gambiae gene names are given for GenBank Accession number or peptide name (Riehle et al. 2002) when available.

${ }^{\mathrm{f}}$ Apis mellifera gene names are given for annotation number (Hummon et al. 2006) or GenBank accession number. 


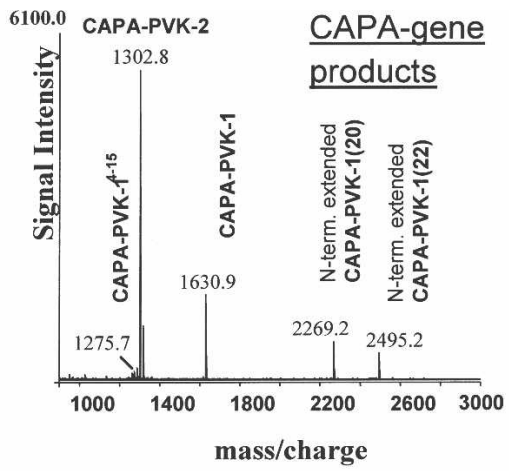

MKTFLIYSACVVLFCIANCQGEPKEPKRNKLASVYALTPSLRVGRRSEGT $\frac{\text { CAPA-PVK-1 }}{\text { CAPA-PVK-1(22 and 20) }}$

DVKRRIGKMVSFPRIGRSESNWVPDDNSYGAORPGANSGGMWFGPRLGRV CAPA-PVK-2

QKRSENFTPWAYIILNGEAPIIREVHYSPRLGRESEEAYEE ILDSNLDVL

Figure 1. Representative MALDI-TOF mass spectrum of a single anterodorsal ganglionic sheath preparation of abdominal ganglion-2 (neurohemal release site of CAPA-peptides) of an adult Tribolium. The direct mass spectrometric screening of nervous tissues may provide reproducible semiquantitative data. Note the different abundances of the expressed capa peptides. CAPA-PVK-1, which is present with a number of truncated/extended forms, has a lower signal intensity than CAPA-PVK-2; CAPA-pyrokinin is not detectable at all. Lower panel shows the annotated sequence with thick gray lines for the peptides determined in the mass spectrometric analysis as shown in the upper panel. Underlines are for putative mature peptides containing C-terminal -PRX motifs, and the letters with gray backgrounds are canonical signals for amidations and/or basic cleavages. Putative signal peptide is boxed.

ally exclusive ways of alternative splicing are conserved in several insect orders (Dai et al. 2007).

\section{Insulin-like peptides and neuroparsin}

Four genes encoding insulin-like peptides (ILP) were identified in the Tribolium genome and assigned to three evolutionary groups: one to ILP-A, two to ILP-B, and one to ILP-C (Fig. 2).

The largest group, ILP-B, contains highly diverse genes including recently duplicated genes in mosquitoes (AgILP1 and AgILP7, and AgILP3 and AgILP6 in Fig. 2). Phylogenetic analysis within the group was not successful because of the highly diverged sequences resulting in a low statistical support for most of the clades. However, a strict conservation of the cysteine motif CCxxxC (also typical for vertebrate insulins) was found in the A chain. The ILP-B group includes the multiple copies of bombyxin-like peptides, which have originally been isolated from the silkworm brain (Nagasawa et al. 1986) based on their stimulating activity of adult development of debrained pupae (Nagasawa et al. 1980). Two closely related Tribolium ILP genes, TcILP1 and TcILP2, were identified and classified within this group.

By contrast, the ILP-A and -C groups are characterized by the CCxxxxC-motif, with four amino acids between the cysteine residues. All insect ILP-A members display high sequence homology, particularly of the A- and B-chain regions. The ILP-A group has not been identified in the honeybee nor in the silkworm genomes. The ILP-C group is further characterized by a very short or absent C-peptide between the A- and B-chains and a single putative mono- or dibasic cleavage signal between the A- and B- chains (Fig. 2). The ILP-C group comprises mammalian insulinlike growth factors (i.e., IGF-1b of human P05019) and a large number of ILPs (named INS) in Caenorhabditis elegans (Duret et al. 1998; Li et al. 2003). Tribolium ILP3 and ILP4 are members of the ILP-A and ILP-C groups, respectively (Fig. 2).

Neuroparsins are structurally similar to the mosquito ovary ecdysteroidogenic hormone and to the vertebrate insulin-like growth factor binding proteins (Schoofs et al. 1997; Brown et al. 1998). We identified one copy of neuroparsin in the Tribolium genome (Fig. 3). In locusts, multiple isoforms (four or more) and multiple functions have been described for this family of proteins (Janssen et al. 2001; Claeys et al. 2003), including an antidiuretic function (Fournier et al. 1994), an involvement in phase transition (Claeys et al. 2005), and a function for neural growth (Vanhems et al. 1990). In the honeybee, a neuroparsin-like protein has been described as queen brain-selective protein-1 (GenBank accession no. Q1T786), implying a potential role of neuroparsin in cast determination, possibly by antagonizing the insulin pathway, similar to the function of vertebrate insulin-like growth factor binding proteins. The ancestral neuroparsin gene appears to have undergone considerable changes particularly in the lineage of higher dipteran insects, similar to the divergence observed in the ovary ecdysteroidogenic hormone in mosquitoes (Brown and Cao 2001). The neuroparsin gene is absent in Drosophila.

\section{Novel osmoregulatory neuropeptide genes in Tribolium}

The Tribolium genome revealed three groups of osmoregulatory neuropeptide genes: One gene encoding an arginine vasopressinlike peptide (AVPL), five genes encoding antidiuretic factors (ADFs), and one gene giving rise, by alternative splicing, to two corticotropin releasing factor (CRF)-like diuretic hormones DH37 and DH47.

The gene encoding AVPL is absent in all other holometabolous insects with a sequenced genome (Table 1). In addition, an AVPL GPCR has been identified in Tribolium, which is also not found in other holometabolous insects (Hauser et al. 2007), further supporting the presence of AVPL signaling pathways in Tribolium and their absence in the other mentioned insects. The AVPL gene has a remarkably conserved overall structure. The $\mathrm{N}$-terminal signal peptide is followed by AVPL and immediately thereafter by a neurophysin-like sequence containing the conserved 14 cysteine amino acid residues (Fig. 4; Supplemental Data 1). In mammals, neurophysin is thought to play an essential role in the proper cellular processing of pro-AVP and to bind to the mature AVP peptide (de Bree and Burbach 1998). As the neurophysin sequence is conserved in Tribolium (Fig. 4), its function may be conserved as well.

The first evidence for an AVPL in insects was revealed by an antibody raised against vertebrate AVP, which stained neurosecretory cells in the CNS of locusts (Proux and Rougon-Rapuzzi 1980; Proux et al. 1987). This locust AVPL was later purified from neuroendocrine extracts, and its diuretic activity was shown by using the isolated locust Malpighian tubules in the Ramsey assay (Proux et al. 1987). This function was later questioned by an independent study (Coast et al. 1993). The absence of the avpl gene in the honeybee, which is the most ancestral order of the holometabolous insects (Savard et al. 2006), indicates that the avpl gene has probably been lost in other holometabolous branches at least two times. However, AVP-related peptides have been described in a number of other invertebrates (Fig. 4) and play a role in reproductive behavior and osmoregulation (Fujino

\section{Genome Research}

www.genome.org 
(A)

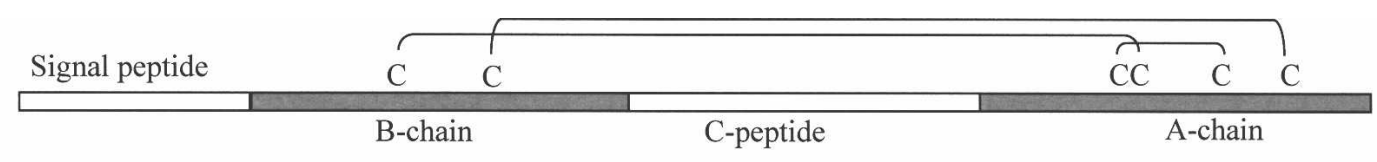

(B) ILP-A

Anopheles Ilp5 Tribolium Ilp4 Drosophila Ilp7

Anopheles Ilp5 Tribolium Ilp4 Drosophila Ilp7

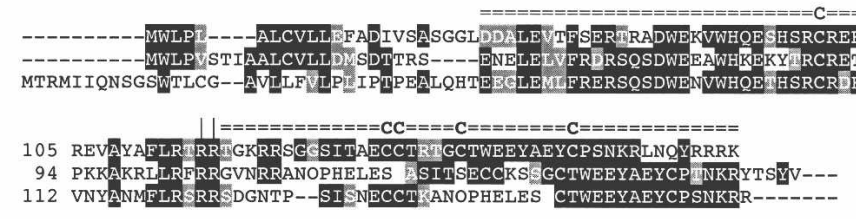

(C) ILP-B
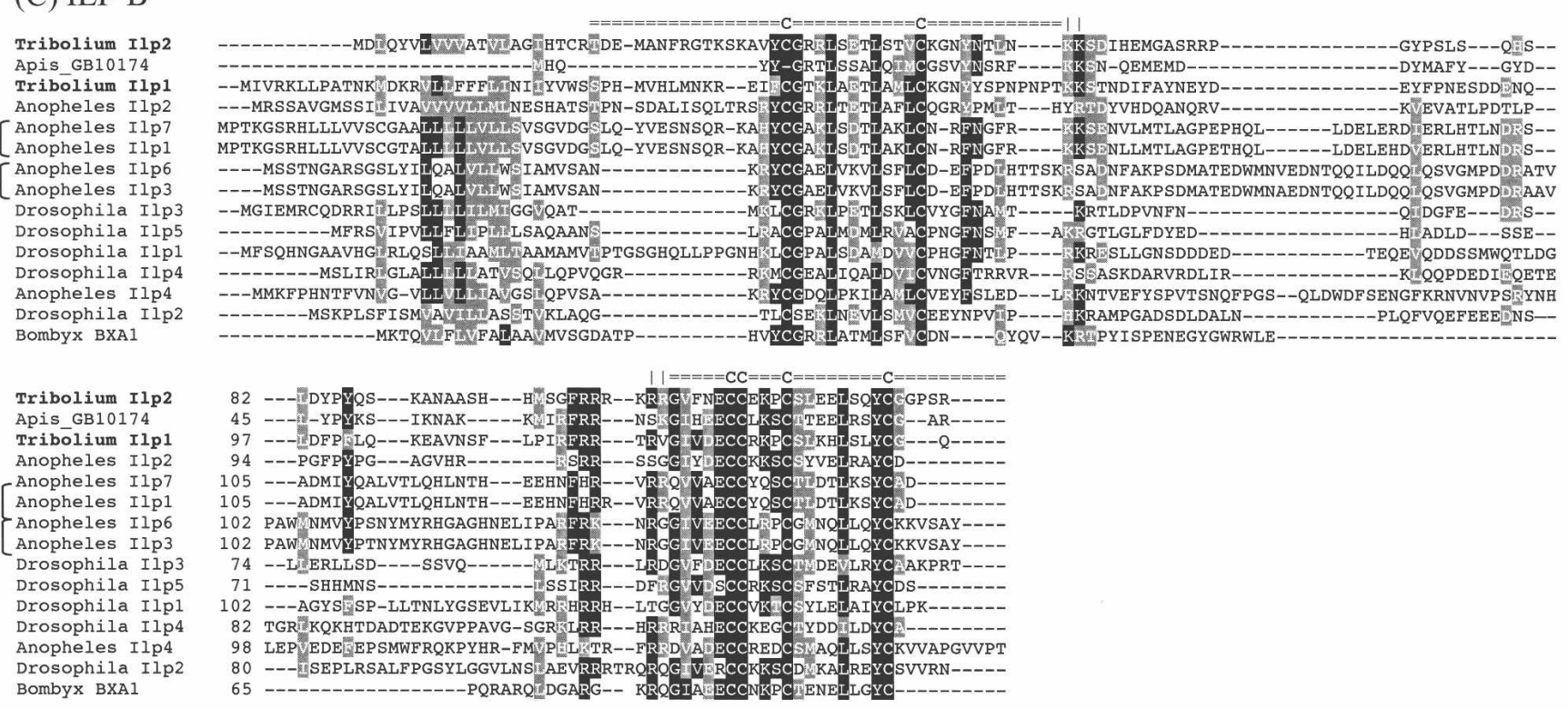

(D) ILP-C

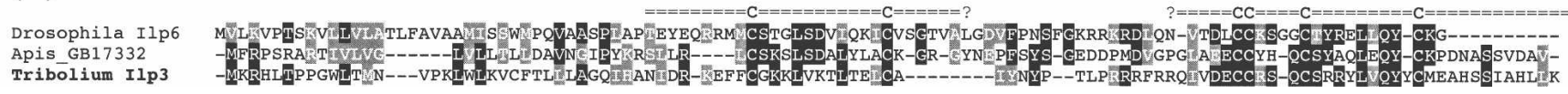

Figure 2. Structure of typical preproinsulin-like peptides $(A)$ and sequence alignment of insulin-like peptide from Tribolium castaneum, Apis mellifera, Anopheles gambiae, Drosophila melanogaster, and one Bombyx mori Bombyxin (BBXA1, P33718) (B-D). Conserved cysteines are marked by "C" on the top of putative A- and B-chains (double lines, $=$ ) with canonical dibasic cleavage sites as vertical bars $(\mathrm{I})$ and unknown cleavage sites as question marks (?). Tribolium and Apis sequences are from their genome database, Drosophila genes are from FlyBase, and Anopheles sequences are from Riehle et al. (2002).

et al. 1999; Kanda et al. 2005; Levoye et al. 2005); comparable functions have been attributed to vasopressin/oxytocin in mammals.

The other group of peptides, ADFs, was known only from a very closely related beetle, Tenebrio molitor, which, like Tribolium, also lives in very dry ecosystems. In T. molitor, two ADFs (ADFa and $\mathrm{ADFb}$ ) inhibit diuretic activity of the Malpighian tubules (Eigenheer et al. 2002, 2003; Wiehart et al. 2002). Surprisingly, ADFs show high degrees of sequence identity to the $\mathrm{C}$ terminus of a cuticle protein from T. molitor (Baernholdt and Anderson 1998). In the Tribolium genome, we identified five putative ADF-b genes, homologous to each other, each containing a highly conserved ADF-b at the $\mathrm{C}$ terminus of the putative gene products (Fig. 5). These five ADF-b genes are all clustered within $10 \mathrm{~kb}$ in linkage group 7 and show similar gene structures, suggesting that they arose by recent gene expansions. It is possible that genes encoding ADF-b only exist in drought-tolerant coleop-

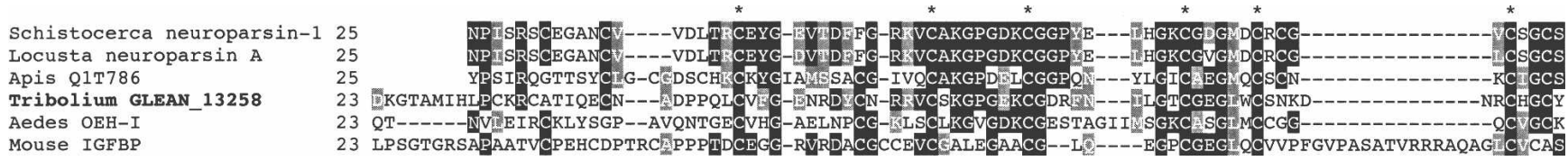
Mouse IGFBP

23 LPSGTGRSAPAATVCPEHCDPTRCFPPPTDCEGG-RVRDACGCCEVCEALEGAACG--IE---EGPCGEGUCVVPFGVPASATVRRRAQAGCVICAS

Figure 3. Sequence alignment of insect neuroparsin and related sequences. The sequences are from Schistocerca gregaria neuroparsin precursor 1 (AC38869), Locusta migratoria neuroparsin A precursor (P10776), Apis mellifera queen brain-selective protein-1 (Q1T786), Aedes aegypti ovarian ecdysteroidogenic hormone I (AAD00823), and Mus musculus insulin-like growth factor binding protein 5 protease (Mm IGFBP). Strictly conserved cysteines are marked with asterisks $\left(^{*}\right)$ on the top of the sequence alignment. 
Salmon Vasotocin Salmon Isotocin

Tribolium AVP-like

Annelid Annetocin

Octopus Cephalotocin

octopus Octopressin

snail Conopressin
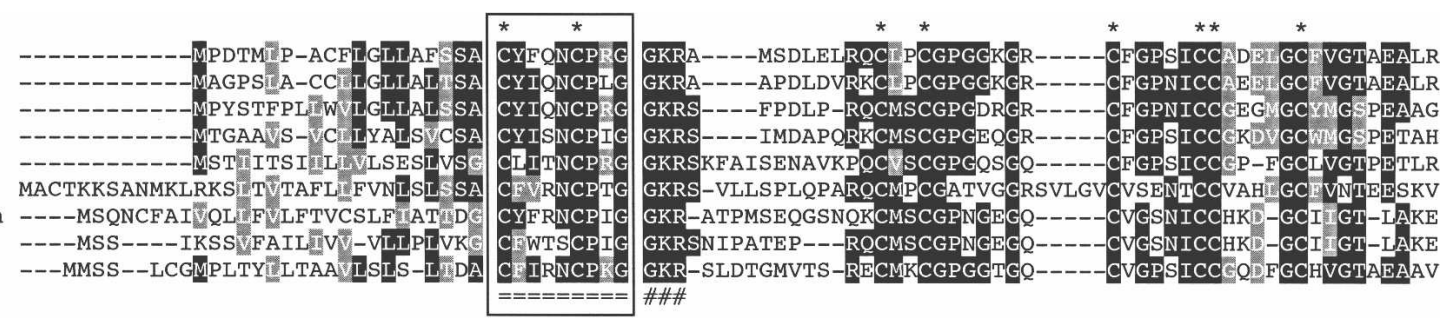

Human AVP

Human OT

salmon Vásotocin

Salmon Isotocin

Tribolium AVP-1 $\overline{i k e}$

Annelid Annetocin

Octopus Cephalotocin

Octopus Octopressin

Snail Conopressin

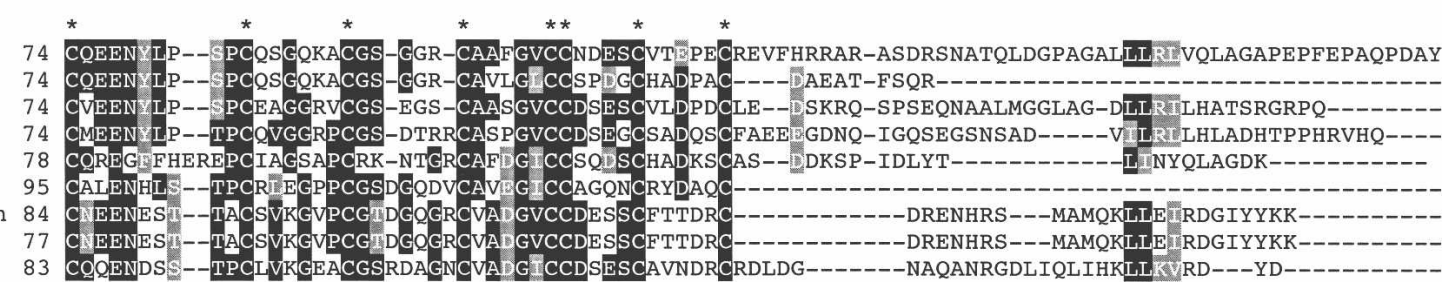

Figure 4. Sequence alignment for the arginine-vasopressin (AVP) and oxytocin prepropeptide family. Sequences in the box are for mature peptides with canonical amidation and dibasic sequences (\#). Strictly conserved 16 cysteines are marked with asterisks $\left({ }^{*}\right)$ on the top of the sequence alignment. GenBank accession nos. for the sequences are AAB86629, AAL92860, BAA01736, BAD12146, ABN79655, BAA36458, BAC82436, BAC82435, and Q00945.

teran insects, since we could not find ADF-b in other holometabolous insects with a sequenced genome. We were unable to identify the ADF-a sequence in the Tribolium genome. The ADF peptides were not detected in the mass spectrometric analyses.

There are two diuretic hormone genes in Tribolium, one yielding DH31 and one yielding two different, but homologous CRF-like diuretic hormones, DH37 and DH47 (Supplemental Data 1). DH37 and DH47 are encoded by two separate exons that are alternatively spliced to a common $5^{\prime}$ exon encoding the signal peptide (Fig. 6). This alternative splicing is not found in Drosophila, where there is only one CRF-like diuretic hormone DH44 (Cabrero et al. 2002). In Tribolium, DH37 and DH47 are correlated with two GPCRs that are found in the clade with the DH44 receptor of $D$. melanogaster (Hauser et al. 2007), suggesting that there may be two separate CRF-like DH signaling pathways in the beetle.

The amino acid sequence of Tribolium DH47 is identical to that of the previously isolated DH47 from T. molitor (Furuya et al.
1998). T. molitor also contains a DH-37-like peptide sharing an amino acid sequence identity of 73\% with DH37 from Tribolium (Furuya et al. 1995). This suggests that T. molitor has two CRF-like DH signaling systems, similar to T. castaneum. Thus, compared to other insects with a completely sequenced genome (A. gambiae, Apis mellifera, B. mori, and D. melanogaster), Tribolium has several additional osmoregulatory peptides (AVP, ADFs, and one extra copy of $\mathrm{DH}$ ) that might be important for the animal to survive in its dry habitats.

\section{Putative neuropeptide genes in Tribolium}

The NPLP1 gene, a gene displaying all typical hallmarks of a neuropeptide precursor gene, was first identified in D. melanogaster by a peptidomics analysis (Baggerman et al. 2002) and by immunocytochemistry (Verleyen et al. 2004). However, its physiological role is unknown, so far. The orthologous NPLP1 gene in
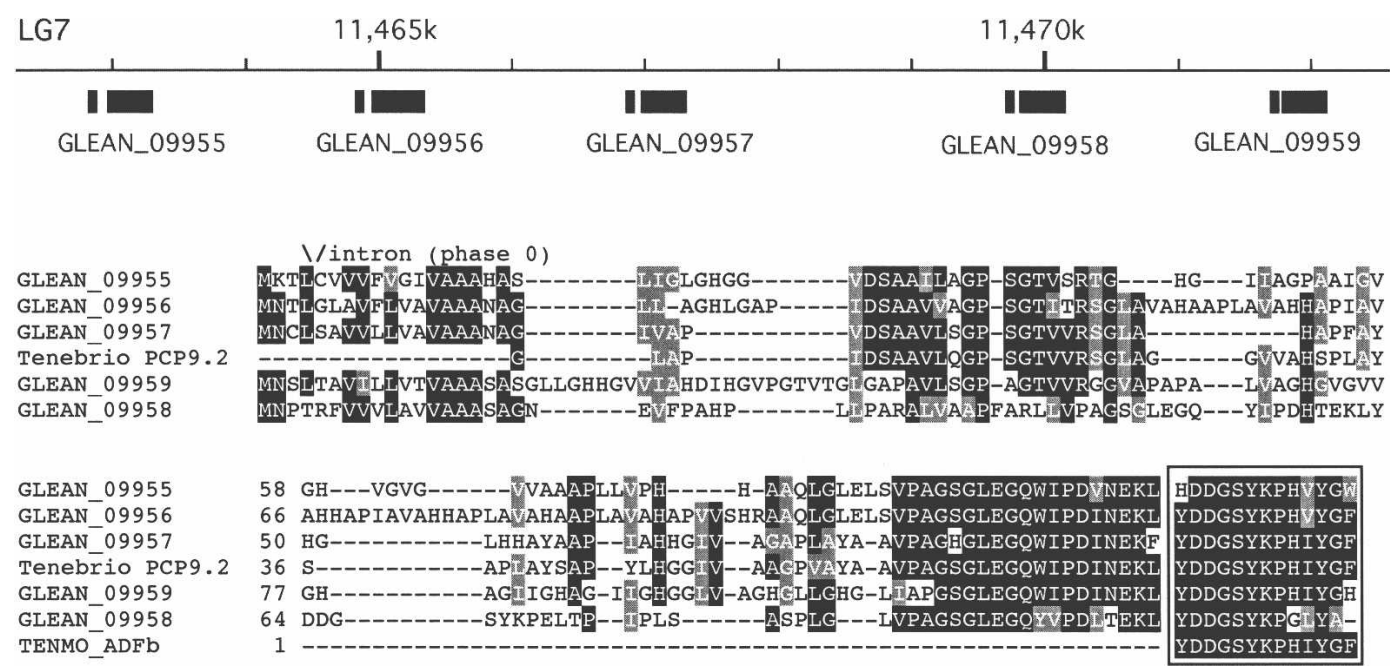

Figure 5. Structure of the genomic region containing five clustered genes for Tribolium castaneum ADF-b1 to -5 (GLEAN 09955-09959; upper panel) and sequence alignment of the five ADF-b with Tenebrio molitor ADF-b (P83109) and cuticle protein TmPCP9.2 (Baernholdt and Anderson 1998). The putative mature peptides located at the carboxy termini are indicated by a box. The conserved intron position is marked on the top of the sequence alignment. Note that all five ADF-b genes are predicted to have small introns at the homologous position in the signal peptides with phase 0.

\section{Genome Research \\ www.genome.org}


(A)

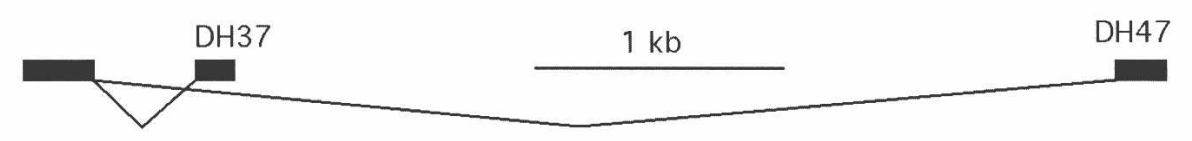

(B)
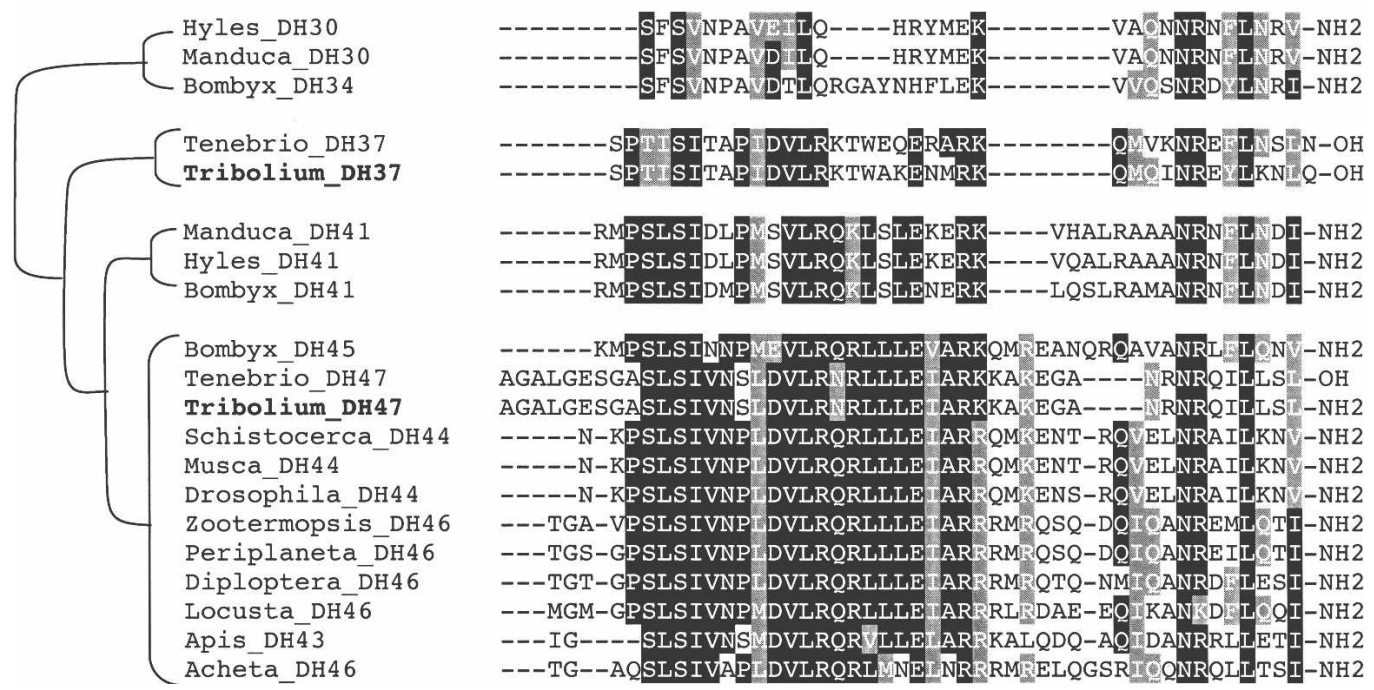

Figure 6. Sequence alignment and phylogenetic relationships of insect corticotropin releasing factor (CRF)-like diuretic hormones (DH). The hypothetical tree implies possible evolutionary relationships among the DHs from different species of insects. Sequences are from Hyles_DH30 (P82015), Manduca_DH30 (P24858), Tenebrio_DH37 (P56618), Tribolium_DH37 (GLEAN_02243), Manduca_DH41 (AAB59200.1), Hyles_DH41 (P82014), Tenebrio_DH47 (P56619), Tribolium_DH47, Schistocerca_DH44 (P67801), Musca_DH44 (P67800), Drosophila_DH44 (NP_649922.2), Zootermopsis_DH46 (P82707), Periplaneta_DH46 (P41538), Diploptera_DH46 (P82373), Locusta_DH46 (AAB19827.1), Apis_DH43 (CAAl45289.1), and Acheta_DH46 (P23834). The three Bombyx DHs were from the GenBank genome database. Amino acid numbers are not indicated because many have only mature peptide sequences in the GenBank.

Tribolium encodes a large number of putative neuropeptides without similarities to each other or to other known neuropeptides (Supplemental Data 1). MS revealed six mature NPLP peptides (Supplemental Data 2).

Several peptides identified in a recent peptidomics study of the honeybee have been tentatively named after their partial $\mathrm{N}$-terminal peptide sequences, i.e., NVP-containing, IDLcontaining, and ITG-containing peptides (Hummon et al. 2006). Analysis of the Tribolium genome also revealed the genes encoding NVP-, IDL-, and ITG-like peptides. Both NVP-like and ITGlike cDNA sequences, were also found in the EST database of Tribolium. MS analysis yielded seven processed peptides from the NVP-like peptide precursor and one peptide from the ITG-like precursor (Supplemental Data 1 and 2). Their function and status as neuropeptides remain elusive.

\section{Expansions of neuropeptide genes in Tribolium}

Expanded neuropeptide genes in the Tribolium genome are those coding for ADF-b, adipokinetic hormones (AKH), eclosion hormones, and insulin-like peptides. Obviously, some of these genes involve recent gene expansions (i.e., five clustered genes for ADFb), whereas others could have been from ancestral gene duplications. As described earlier, the gene encoding the CRF-like diuretic hormones (DH37/47) has not been duplicated, but two different transcripts are generated by alternative splicing. A similar alternative splicing occurs in the gene encoding the iontransporting peptides ITP-a and ITP-b.
Three genes for AKH-like peptides were found in the Tribolium genome. Predicted prepropeptides have common structures with signal peptides for secretion directly followed by the immature peptides and an additional C-terminal conserved region surrounding two conserved cysteines. The two Tribolium AKHs-TcAKH1 and TcAKH2-are similar to each other, while another containing TcAKH3 is more divergent and has mild homology with the sequences found in mosquito species (Fig. 7). Sequence similarity among different insect AKH prepropeptides suggests that there are at least two distinct ancestral forms. The Drosophila genome contains only one AKH gene copy, which implies the loss of at least one lineage in Drosophila. AKHs of insects are usually synthesized in the glandular portion of the corpora cardiaca (CC) but not in the central nervous system itself. Direct profiling of the CC by MALDI-MS as well as analyses of CC-extracts by ESI-MS revealed the expression of AKH-2, whereas AKH-1 and AKH-3 could not be observed.

Eclosion hormone (EH) is known for its involvement in ecdysis behavior (Truman 2005). In contrast to other insects where only one Eh gene per genome appears to be common, the Tribolium genome contains two genes, one encoding $\mathrm{EH}$ that is highly conserved with the previously known EHs in other species, and another encoding an EH-like peptide (Fig. 8).

\section{Neuropeptide genes lacking in Tribolium}

Several neuropeptide genes are apparently lacking in the Tribolium genome. These include neuropeptide F, pigment dispers- 

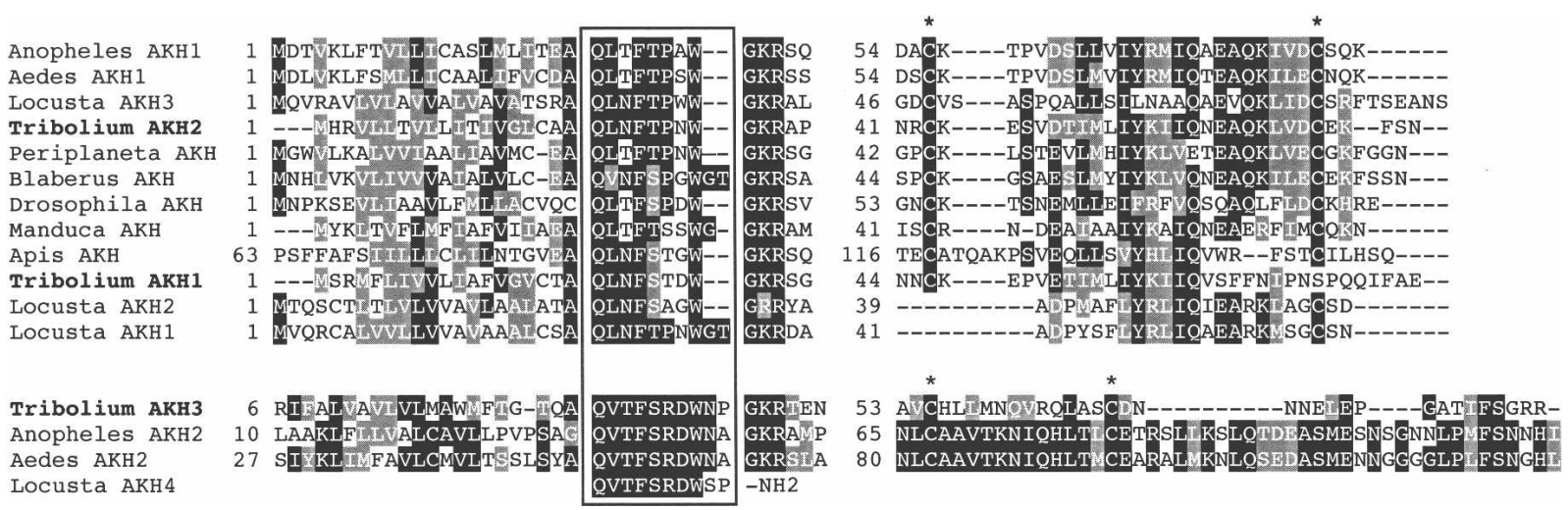

Figure 7. Sequence alignment of adipokinetic hormones (AKH). The mature peptides are in the box and followed by the glycine required for amidation and dibasic cleavage sites. Conserved cysteines are marked by asterisks $\left(^{*}\right)$ on the top of the alignment. Note that the middle of the sequence is omitted. Sequences are from Anopheles_AKH1 (ABD43194.1), Aedes_AKH1(EAT35885.1), Locusta_AKH3 (P19872), Periplaneta_AKH (AAV41425.1), Blaberus_AKH (Q17128), Drosophila_AKH (NP_523918.1), Manduca_AKK (P67788), Apis_AKH (from Hummon et al. 2006), Locusta_AKH2 (P08379), Locusta_AKH1 (P55319), Anopheles_AKH2 (ABD60145.1), Aedes_AKH2 (EAT37004.1), and Locusta_AKH4 (Siegert 1999).

ing factor (PDF), ADF-a, orcokinin, corazonin, kinin, and allatostatin-A. Interestingly, for the latter three, their cognate GPCRs also have not been found in the Tribolium genome (Hauser et al. 2007), supporting the lack of these peptidergic signaling systems in the beetle. For the other peptide genes, however, some of the "absence" could have been caused by missing sequences in the current version of the genome assembly or by highly diverging sequences not detected by our homology-based searches. Again, the loss of these signaling systems, together with the gains discussed earlier, shows that the Tribolium endocrine system is quite different from that of other insects with a sequenced genome.

\section{Methods}

\section{Gene identification}

The whole genome sequence of Tribolium castaneum, version 2.0, was used for the homology searches at the Web site of the Human Genome Sequence Center, Baylor College of Medicine (http://www.hgsc.bcm.tmc.edu/blast/blast.cgi?organism= Tcastaneum), or in the local BLAST by using BLosum62 or PAM30 for searching the short matching sequences. Prediction of the gene structure and open reading frame was done in GENBOREE (http://www.genboree.org) that contains the GLEAN2 predictions incorporating the results from multiple gene-prediction software programs and by manual correction. The homology search was followed by a prediction of the gene structure. The signal peptide in the N-terminal was predicted by the SIGNALP server (Bendtsen et al. 2004) (http://www.cbs.dtu.dk/services/ SignalP/). Identifying the N-terminal signal peptide sometimes overrode the largest open reading frame of the gene in the pre- diction. Thus, the second translation initiation site is preferred in some cases (Supplemental data 1).

Mining EST data was done using the NCBI non-redundant database and trace archives (http://www.ncbi.nlm.nih.gov/ Traces/trace.cgi). RT-PCR to confirm the presence of transcripts was applied using the primers designed on the highly conserved regions in the gene predictions. Details of primer information will be published elsewhere. Multiple sequence alignment was performed in ClustalW (http://www.ebi.ac.uk/clustalw/) (Thompson et al. 1994) with manual adjustment. Phylogenetic analysis was done using PAUP 4.08 (Swofford 2000). Box shading in the sequence alignments was made with inverted fonts, with black (identical) and gray (similar) for $50 \%$ majority rules in the alignment.

The transcript of each gene was confirmed by either reverse transcription PCR or EST sequences (http://www.ncbi.nlm.nih. gov/dbEST/index.html; Park et al. 2007). List of the primers used in the RT-PCR is in Table 2.

\section{Sample preparation for MS}

Different parts of the CNS and peptide release sites (retrocerebral complex, thoracic perisympathetic organs, abdominal perisympathetic organs, Inka cells) were first directly analyzed on a MALDI-TOF mass spectrometer. The resulting ion signals were compared with the theoretical masses of the predicted peptides. A number of ions could be fragmented on the matrix-assisted laser desorption ionization time-of-flight (MALDI-TOF) MS, but most of the fragmentations were subsequently done using an ESI-Q-TOF MS and extracts of 30 brains, 30 thoracic ganglia, and 50 corpora cardiaca, respectively.

Manduca EH
Helicoverpa EH
Ostrinia EH
Bombyx EH
Apis EH
Aedes EH
Tribolium EH
Romalea EH
Drosophila EH
Tribolium EHL

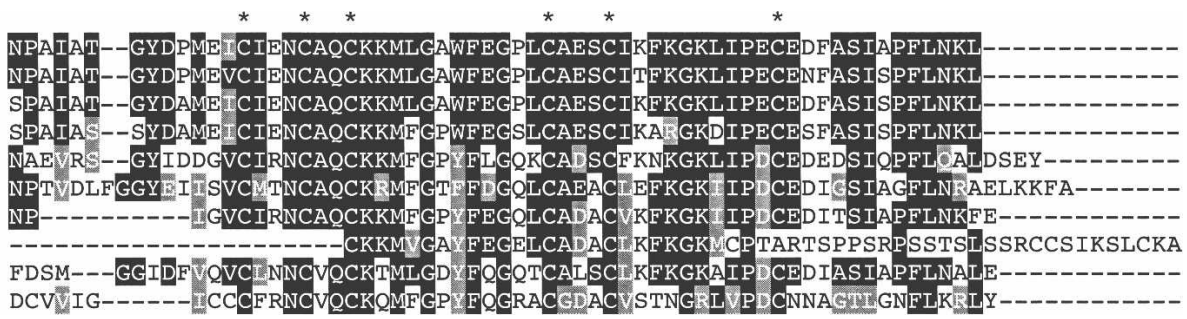

Figure 8. Sequence alignment of eclosion hormones (EH). The six conserved cysteines are marked by asterisks (*) on the top of the alignment. Sequences are from Manduca_EH (P11919), Helicoverpa_EH (AAV69026.1), Ostrinia_EH (ABG66962.1), Bombyx_EH (P25331), Apis_EH (XP_001122120.1), Aedes_EH (EAT41662.1), Romalea_EH (AAD28480.1), and Drosophila_EH (CAA51050.1).

\section{Genome Research}

www.genome.org 
Table 2. List of primers used for RT-PCR to confirm the transcript of predicted neuropeptide and protein hormone gene

\begin{tabular}{|c|c|c|}
\hline Gene name & Forward primer $\left(5^{\prime}\right.$ to $\left.3^{\prime}\right)$ & Reverse primer $\left(5^{\prime}\right.$ to $\left.3^{\prime}\right)$ \\
\hline AKH-1 & GGGTGTGTACCGCTCAGTTA & GGCGAATTGGGAATATTGAA \\
\hline AKH-2 & ATCACCATTGTGGGTTTGTG & TCACAGTCCACTAАTTTCTG \\
\hline Allatostatin-B & CTGCGGGTAAACCACCAC & TTGTCССАСТTGСТССТСТT \\
\hline AVP-like & CGTGAGGGCTTTTTCCACGA & TTTATCGTCACTGGCACAGC \\
\hline Bursicon-alpha subunit & AAATCCAGGTTTCGGGGGCT & GAAACCGAAGCTTCCCGCTC \\
\hline Bursicon-beta subunit & ACAGAGAATATGCAATGGGG & GAGACGCACGCCGTCAGGGT \\
\hline CCAP & ATGTGGGCGCAAACGCTCGA & GGCAGGGACAGCAGCGTCCT \\
\hline Calcitonin-like diuretic hormone (DH31) & TCCCGAATATСТССТССAGA & TATGCTTCTTCTTCGCTTCG \\
\hline Corticotropin releasing factor like-DH (DH37) & TGGAGCCCGTTGATGTAGCT & CGCATGTTCTCTTTTGCCCA \\
\hline Corticotropin releasing factor like-DH (DH-47) & TGGAGCCCGTTGATGTAGCT & AACGTCCAACGAATTCACAA \\
\hline $\mathrm{EH}$ & GAAATTTCCTCGTCCTTTTG & GTTCAAAAAGGGCGCAATCG \\
\hline ETH & GCTGCCAAAAATGTGCCCAG & AACCGACGGATCATCCCCCA \\
\hline ITP-a & ATGAATTACCGATCATCCAA & СTAAATTAAGTTAGTGTGTTAG \\
\hline ITP-b & ATGAATTACCGATCATCCAA & TTACTTCGATAAATATTCAATCA \\
\hline
\end{tabular}

Dissection of nervous tissues was performed as described for D. melanogaster (Predel et al. 2004). Since in T. castaneum the ventral nerve cord does not develop median nerves, release sites of putative FMRFamides, CAPA-peptides, and ETHs were studied by immunocytochemistry prior to the experiments (not shown). Dissected tissues were transferred with the help of a glass capillary to a stainless steel sample plate for MALDI-TOF MS or into a chilled solution of $5 \mu \mathrm{L}$ of methanol/water/trifluoroacetic acid (90:9:1, v/v/v) for electrospray ionization quadrupole time-offlight MS (ESI-Q-TOF MS).

\section{MALDI-TOF MS}

Dissected nervous tissues were dried on the sample plate and subsequently rinsed with water to reduce salt contamination. Matrix solution ( $\alpha$-cyano-4-hydroxycinnamic acid dissolved in methanol/water) was pumped onto the dried preparations over a period of $\sim 5$ sec using a Nanoliter injector (World Precision Instruments). Each preparation was allowed to dry and then covered with pure water for a few seconds which was removed by cellulose paper. At least five preparations each were prepared for mass spectrometric analyses which were performed as described in Predel et al. (2007).

\section{ESI-Q-TOF MS}

Following the dissection procedure, $50 \mu \mathrm{L}$ of $0.1 \%$ TFA was added to the $5-\mu \mathrm{L}$ methanol/water/trifluoroacetic acid solution. The extract was sonicated and centrifuged, and the methanol was evaporated from the supernatant. The resulting aqueous supernatant was then loaded onto an activated and equilibrated home-made microcolumn (Luna C18 material [10 $\mu \mathrm{m}]$; Phenomenex). Subsequent mass spectrometric analyses were performed as described in Predel et al. (2004).

\section{Acknowledgments}

This study was funded by USDA-NRI-CRSEES 2007-35604-17759, NSF IOS-0615818, the German Research Foundation (Predel 595/ 6-4), Danish Research Agency, and Novo Nordisk Foundation. P.V. is a postdoctoral fellow of the Fund for Scientific Research Flanders (F.W.O. Vlaanderen). The publication is Contribution Number 07-229-J from Kansas Agricultural Experimental Station.

\section{References}

Baernholdt, D. and Anderson, S.O. 1998. Sequence studies on post-ecdysial cuticular proteins from pupae of the yellow mealworm, Tenebrio molitor. Insect Biochem. Mol. Biol. 28: 517-526.
Baggerman, G., Cerstiaens, A., De Loof, A., and Schoofs, L. 2002. Peptidomics of the larval Drosophila melanogaster central nervous system. J. Biol. Chem. 277: 40368-40374.

Bendtsen, J.D., Nielsen, H., von Heijne, G., and Brunak, S. 2004. Improved prediction of signal peptides: SignaLP 3.0. J. Mol. Biol. 340: 783-795.

Brown, M.R. and Cao, C. 2001. Distribution of ovary ecdysteroidogenic hormone I in the nervous system and gut of mosquitoes. J. Insect Sci. 1: 3 .

Brown, M.R., Graf, R., Swiderek, K.M., Fendley, D., Stracker, T.H., Champagne, D.E., and Lea, A.O. 1998. Identification of a steroidogenic neurohormone in female mosquitoes. J. Biol. Chem. 273: 3967-3971.

Cabrero, P., Radford, J.C., Broderick, K.E., Costes, L., Veenstra, J.A. Spana, E.P., Davies, S.A., and Dow, J.A. 2002. The Dh gene of Drosophila melanogaster encodes a diuretic peptide that acts through cyclic AMP. J. Exp. Biol. 205: 3799-3807.

Cazzamali, G., Torp, M., Hauser, F., Williamson, M., and Grimmelikhuijzen, C.J.P. 2005. The Drosophila gene CG9918 codes for a pyrokinin-1 receptor. Biochem. Biophys. Res. Commun. 335: $14-19$.

Claeys, I., Simonet, G., Van Loy, T., De Loof, A., and Vanden Broeck, J. 2003. cDNA cloning and transcript distribution of two novel members of the neuroparsin family in the desert locust, Schistocerca gregaria. Insect Mol. Biol. 12: 473-481.

Claeys, I., Simonet, G., Breugelmans, B., Van Soest, S., Franssens, V., Sas, F., De Loof, A., and Vanden Broeck, J. 2005. Quantitative real-time RT-PCR analysis in desert locusts reveals phase dependent differences in neuroparsin transcript levels. Insect Mol. Biol. 14: $415-422$.

Coast, G.M., Rayne, R.C., Hayes, T.K., Mallet, A.I., Thompson, K.S., and Bacon, J.P. 1993. A comparison of the effects of two putative diuretic hormones from Locusta migratoria on isolated locust Malpighian tubules. J. Exp. Biol. 175: 1-14.

Dai, L., Zitnan, D., and Adams, M.E. 2007. Strategic expression of ion transport peptide gene products in central and peripheral neurons of insects. J. Comp. Neurol. 500: 353-367.

de Bree, F.M. and Burbach, J.P. 1998. Structure-function relationships of the vasopressin prohormone domains. Cell. Mol. Neurobiol. 18: $173-191$.

Duret, L., Guex, N., Peitsch, M.C., and Bairoch, A. 1998. New insulin-like proteins with atypical disulfide bond pattern characterized in Caenorhabditis elegans by comparative sequence analysis and homology modeling. Genome Res. 8: 348-353.

Eigenheer, R.A., Nicolson, S.W., Schegg, K.M., Hull, J.J., and Schooley, D.A. 2002. Identification of a potent antidiuretic factor acting on beetle Malpighian tubules. Proc. Natl. Acad. Sci. 99: 84-89.

Eigenheer, R.A., Wiehart, U.M., Nicolson, S.W., Schoofs, L., Schegg, K.M., Hull, J.J., and Schooley, D.A. 2003. Isolation, identification and localization of a second beetle antidiuretic peptide. Peptides 24: $27-34$.

Eipper, B.A., Milgram, S.L., Husten, E.J., Yun, H.Y., and Mains, R.E. 1993. Peptidylglycine alpha-amidating monooxygenase: A multifunctional protein with catalytic, processing, and routing domains. Protein Sci. 2: 489-497.

Fournier, B., Guerineau, N., Mollard, P., and Girardie, J. 1994. Effects of two neuronal antidiuretic molecules, neuroparsin and 5-hydroxytryptamine, on cytosolic free calcium monitored with indo-1 in epithelial and muscular cells of the African locust rectum. 
Biochim. Biophys. Acta 1220: 181-187.

Fujino, Y., Nagahama, T., Oumi, T., Ukena, K., Morishita, F., Furukawa, Y., Matsushima, O., Ando, M., Takahama, H., Satake, H., et al. 1999. Possible functions of oxytocin/vasopressin-superfamily peptides in annelids with special reference to reproduction and osmoregulation. J. Exp. Zool. 284: 401-406.

Furuya, K., Schegg, K.M., Wang, H., King, D.S., and Schooley, D.A. 1995. Isolation and identification of a diuretic hormone from the mealworm Tenebrio molitor. Proc. Natl. Acad. Sci. 92: 12323-12327.

Furuya, K., Schegg, K.M., and Schooley, D.A. 1998. Isolation and identification of a second diuretic hormone from Tenebrio molitor. Peptides 19: 619-626.

Grimmelikhuijzen, C.J.P., Williamson, M., and Hansen, G.N. 2002. Neuropeptides in cnidarians. Can. J. Zool. 80: 1690-1702.

Hauser, F., Cazzamali, G., Williamson, M., Blenau, W., and Grimmelikhuijzen, C.J.P. 2006a. A review of neurohormone GPCRs present in the fruitfly Drosophila melanogaster and the honey bee Apis mellifera. Prog. Neurobiol. 80: 1-19.

Hauser, F., Williamson, M., Cazzamali, G., and Grimmelikhuijzen, C.J.P. 2006b. Identifying neuropeptide and protein hormone receptors in Drosophila melanogaster by exploiting genomic data. Brief. Funct. Genom. Proteom. 4: 321-330.

Hauser, F., Cazzamali, G., Williamson, M., Park, Y., Li, B., Tanaka, Y., Predel, R., Neupert, S., Schachtner, J., Verleyen, P., et al. 2007. A genome-wide inventory of neurohormone GPCRs in the red flour beetle Tribolium castaneum. Front. Neuroendocrinol. (in press).

Hewes, R.S. and Taghert, P.H. 2001. Neuropeptides and neuropeptide receptors in the Drosophila melanogaster genome. Genome Res. 11: $1126-1142$.

Hummon, A.B., Richmond, T.A., Verleyen, P., Baggerman, G., Huybrechts, J., Ewing, M.A., Vierstraete, E., Rodriguez-Zas, S.L., Schoofs, L., Robinson, G.E., et al. 2006. From the genome to the proteome: Uncovering peptides in the Apis brain. Science 314: $647-649$.

Isabel, G., Martin, J.R., Chidami, S., Veenstra, J.A., and Rosay, P. 2005. $\mathrm{AKH}$-producing neuroendocrine cell ablation decreases trehalose and induces behavioral changes in Drosophila. Am. J. Physiol. Regul. Integr. Comp. Physiol. 288: R531-R538.

Janssen, T., Claeys, I., Simonet, G., De Loof, A., Girardie, J., and Vanden Broeck, J. 2001. cDNA cloning and transcript distribution of two different neuroparsin precursors in the desert locust, Schistocerca gregaria. Insect Mol. Biol. 10: 183-189.

Kanda, A., Satake, H., Kawada, T., and Minakata, H. 2005. Novel evolutionary lineages of the invertebrate oxytocin/vasopressin superfamily peptides and their receptors in the common octopus (Octopus vulgaris). Biochem. J. 387: 85-91.

Kim, S.K. and Rulifson, E.J. 2004. Conserved mechanisms of glucose sensing and regulation by Drosophila corpora cardiaca cells. Nature 431: $316-320$

Kim, Y.J., Zitnan, D., Galizia, C.G., Cho, K.H., and Adams, M.E. 2006. A command chemical triggers an innate behavior by sequential activation of multiple peptidergic ensembles. Curr. Biol. 16: $1395-1407$.

Levoye, A., Mouillac, B., Riviere, G., Vieau, D., Salzet, M., and Breton, C. 2005. Cloning, expression and pharmacological characterization of a vasopressin-related receptor in an annelid, the leech Theromyzon tessulatum. J. Endocrinol. 184: 277-289.

Li, W., Kennedy, S.G., and Ruvkun, G. 2003. daf-28 encodes a C. elegans insulin superfamily member that is regulated by environmental cues and acts in the DAF-2 signaling pathway. Genes \& Dev. 17: 844-858.

Liu, F., Baggerman, G., Schoofs, L., and Wets, G. 2006a. Uncovering conserved patterns in bioactive peptides in Metazoa. Peptides 27: $3137-3153$.

Liu, F., Baggerman, G., D’Hetog, W., Verleyen, P., Schoofs, L., and Wets, G. 2006b. In silico identification of new secretory peptide genes in Drosophila melanogaster. Mol. Cell. Proteomic. 5: 510-522.

McNabb, S.L., Baker, J.D., Agapite, J., Steller, H., Riddiford, L.M., and Truman, J.W. 1997. Disruption of a behavioral sequence by targeted death of peptidergic neurons in Drosophila. Neuron 19: 813-823.

Nagasawa, H., Guo, F., Zhong, X.C., Xia, B.Y., Wang, Z.S., Qui, X.J., Wei, D.Y., Chen, E.I., Wang, J.Z., Suzuki, A., et al. 1980. Large-scale purification of prothoracicotropic hormone of the silkworm (Bombyx mori). Sci. Sin. 23: 1053-1060.

Nagasawa, H., Kataoka, H., Isogai, A., Tamura, S., Suzuki, A., Mizoguchi, A., Fujiwara, Y., Suzuki, A., Takahashi, S.Y., and Ishizaki, H. 1986. Amino acid sequence of a prothoracicotropic hormone of the silkworm Bombyx mori. Proc. Natl. Acad. Sci. 83: 5840-5843.

Park, Y., Zitnan, D., Gill, S.S., and Adams, M.E. 1999. Molecular cloning and biological activity of ecdysis-triggering hormones in Drosophila melanogaster. FEBS Lett. 463: 133-138.

Park, Y., Filippov, V., Gill, S.S., and Adams, M.E. 2002a. Deletion of the ecdysis-triggering hormone gene leads to lethal ecdysis deficiency. Development 129: 493-503.

Park, Y., Kim, Y.J., and Adams, M.E. 2002b. Identification of G protein-coupled receptors for Drosophila PRXamide peptides, CCAP, corazonin, and AKH supports a theory of ligand-receptor coevolution. Proc. Natl. Acad. Sci. 99: 11423-11428.

Park, J.H., Schroeder, A.J., Helfrich-Forster, C., Jackson, F.R., and Ewer, J. 2003. Targeted ablation of CCAP neuropeptide-containing neurons of Drosophila causes specific defects in execution and circadian timing of ecdysis behavior. Development 130: 2645-2656.

Park, Y., Aikiins, J., Wang, L.J., Beeman, R.W., Oppert, B., Lord, J.C., Brown, S.J., Lorenzen, M.D., Richards, S., Weinstock, G.M., et al. 2007. Analysis of transcriptome data in the red flour beetle Tribolium castaneum. Insect Biotech. Mol. Biol. (in press).

Predel, R. and Neupert, S. 2007. Social behavior and the evolution of neuropeptide genes: Lessons from the honeybee genome. BioEssays 29: 416-421.

Predel, R. and Wegener, C. 2006. Biology of the CAPA peptides in insects. Cell. Mol. Life Sci. 63: 2477-2490.

Predel, R., Wegener, C., Russell, W.K., Tichy, S.E., Russell, D.H., and Nachman, R.J. 2004. Peptidomics of CNS-associated neurohemal systems of adult Drosophila melanogaster: A mass spectrometric survey of peptides from individual flies. J. Comp. Neurol. 474: 379-392.

Predel, R., Eckert, M., Pollák, E., Molnár, L., Scheibner, O., and Neupert, S. 2007. Peptidomics of identified neurons demonstrates a highly differentiated expression pattern of FXPRLamides in the neuroendocrine system of an insect. J. Comp. Neurol. 500: 498-512.

Proux, J. and Rougon-Rapuzzi, G. 1980. Evidence of vasopressin-like molecule in migratory locust. Radioimmunological measurements in different tissues: Correlation with various states of hydration. Gen. Comp. Endocrinol. 42: 378-383.

Proux, J.P., Miller, C.A., Li, J.P., Carney, R.L., Girardie, A., Delaage, M., and Schooley, D.A. 1987. Identification of an arginine vasopressin-like diuretic hormone from Locusta migratoria. Biochem. Biophys. Res. Commun. 149: 180-186.

Riehle, M.A., Garczynski, S.F., Crim, J.W., Hill, C.A., and Brown, M.R. 2002. Neuropeptides and peptide hormones in Anopheles gambiae. Science 298: 172-175.

Savard, J., Tautz, D., Richards, S., Weinstock, G.M., Gibbs, R.A., Werren, J.H., Tettelin, H., and Lercher, M.J. 2006. Phylogenomic analysis reveals bees and wasps (Hymenoptera) at the base of the radiation of Holometabolous insects. Genome Res. 16: 1334-1338.

Schoofs, L., Veelaert, D., Vanden Broeck, J., and De Loof, A. 1997. Peptides in the locusts, Locusta migratoria and Schistocerca gregaria. Peptides 18: $145-156$.

Siegert, K.J. 1999. Locust corpora cardiaca contain an inactive adipokinetic hormone. FEBS Lett. 447: 237-240.

Swofford, D.L. 2000. PAUP*: Phylogenetic Analysis Using Parsimony (*and Other Methods), Version 4. Sinauer Associates, Sunderland, MA.

Thompson, J.D., Higgins, D.G., and Gibson, T.J. 1994. CLUSTAL W: Improving the sensitivity of progressive multiple sequence alignment through sequence weighting, position-specific gap penalties and weight matrix choice. Nucleic Acids Res. 22: 4673-4680. doi: 10.1093/nar/22.22.4673.

Truman, J.W. 2005. Hormonal control of insect ecdysis: Endocrine cascades for coordinating behavior with physiology. Vitam. Horm. 73: $1-30$.

Vanhems, E., Delbos, M., and Girardie, J. 1990. Insulin and neuroparsin promote neurite outgrowth in cultured locust CNS. Eur. J. Neurosci. 2: 776-782.

Verleyen, P., Baggerman, G., Wiehart, U., Schoeters, E., Van Lommel, A., De Loof, A., and Schoofs, L. 2004. Expression of a novel neuropeptide, NVGTLARDFQLPIPNamide, in the larval and adult brain of Drosophila melanogaster. J. Neurochem. 88: 311-319.

Wiehart, U.I., Nicolson, S.W., Eigenheer, R.A., and Schooley, D.A. 2002. Antagonistic control of fluid secretion by the Malpighian tubules of Tenebrio molitor: Effects of diuretic and antidiuretic peptides and their second messengers. J. Exp. Biol. 205: 493-501.

$\mathrm{Wu}, \mathrm{Q}$. and Brown, M.R. 2006. Signaling and function of insulin-like peptides in insects. Annu. Rev. Entomol. 51: 1-24. Zitnan, D Zitnanova, I., Spalovska, I., Takac, P., Park, Y., and Adams, M.E. 2003. Conservation of ecdysis-triggering hormone signalling in insects. J. Exp. Biol. 206: 1275-1289.

Zitnan, D., Zitnanova, I., Spalovska, I., Takac, P., Park, Y., and Adams, M.E., 2003. Conservation of ecdysis-triggering hormone signalling in insects. J. Exp. Biol. 206: 1275-1289.

Received May 15, 2007; accepted in revised form August 6, 2007.

\section{Genome Research}

www.genome.org 


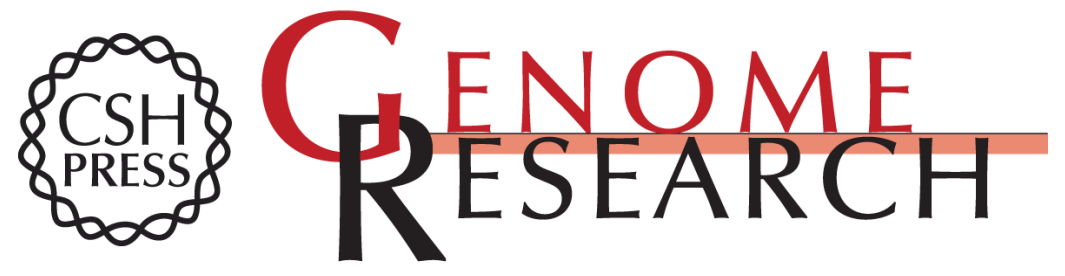

\section{Genomics, transcriptomics, and peptidomics of neuropeptides and protein hormones in the red flour beetle Tribolium castaneum}

Bin Li, Reinhard Predel, Susanne Neupert, et al.

Genome Res. 2008 18: 113-122 originally published online November 19, 2007

Access the most recent version at doi:10.1101/gr.6714008

Supplemental Material

References

License

Email Alerting Service
http://genome.cshlp.org/content/suppl/2007/11/20/gr.6714008.DC1

This article cites 58 articles, 19 of which can be accessed free at: http://genome.cshlp.org/content/18/1/113.full.html\#ref-list-1

Receive free email alerts when new articles cite this article - sign up in the box at the top right corner of the article or click here.

\section{Affordable, Accurate Sequencing.}

